\title{
A Monte Carlo approach for predicting aircraft detection by MANPADS
}

\section{Predição de detecção de aeronaves por MANPADS por meio do Método de Monte Carlo}

\author{
Caio Augusto de Melo Silvestre ${ }^{1}$, Eduarda de Proença Rosa Campos ${ }^{1}$
}

\begin{abstract}
The uprising threat and employment of man-portable air-defense systems (MANPADS) demand a robust planning for air missions, which can enhance the probability of survival of the aircraft and the mission's accomplishment. In an effort to deliver an auxiliary tool for mission planning, an algorithm was developed to deal with the uncertainties in this type of scenario entitled surface-to-air infrared threat modulus (MAISA), based on the Monte Carlo method. This algorithm considers factors such as the MANPADS's position, the aircraft's position, atmospheric transmittance and factors related to MANPADS's infrared detector.
\end{abstract}

Keywords: Infrared radiation, Monte Carlo method, Simulation.

\section{RESUMO}

A crescente ameaça e emprego de MANPADS, demanda um planejamento de missões aéreas robusto, que aumente a probabilidade de sobrevivência da aeronave e de cumprimento da missão. Visando a propiciar uma ferramenta de auxílio ao planejamento de missões aéreas nesse tipo de cenário, foi desenvolvido um algoritmo para lidar com tais incertezas, denominado MAISA, que se baseia no Método de Monte Carlo. Este algoritmo leva em consideração fatores de posição do MANPADS, da aeronave, da transmitância atmosférica e do detector infravermelho do MANPADS e fornece ao planejador de missão aérea uma área de segurança que aeronave deve evitar de acordo com o risco de detecção desejado para a missão.

Palavras-chave: Infravermelho, Método de Monte Carlo, Simulação. 


\section{INTRODUCTION}

Infrared guided missiles, specially man-portable air-defense system (MANPADS), have been escalating all over the world, mainly among nongovernmental forces. Thousands of MANPADS are spread all over Africa, South America and Middle East and can be found in the black market for up to US $\$ 5,000^{1}$. These systems have a relatively use facility due to its portability and mobility. Furthermore, the engagement process with the target is simple since the guided missile is autonomous after launch and passive since there is no emitted radiance for guidance. Therefore, when planning a route in an operational scenario with MANPADS as threats, inherited uncertainties due to this scenario must be accounted.

Previous studies ${ }^{2,3}$ have provided an evaluation metric of an aircraft susceptibility to infrared missiles, considering the missile's detection and cinematic envelope. However, they were restricted to air-to-air engagements and didn't take into account for the uncertainties in a MANPADS operational scenario.

In order to deal with these uncertainties, the mission planning could use the Monte Carlo approach to model this scenario. In consequence, all the known uncertainties in the scenario are considered, providing data capable of assisting decision making with greater robustness.

This study presents the algorithm employed in the surface-to-air infrared threat modulus (MAISA), that uses the Monte Carlo method to deal with all the operational scenarios uncertainties in analysis.

\section{THEORETICAL FRAMEWORK}

Infrared missiles use an optical system to collect infrared radiation and direct it to the missile's sensor, which can be composed of a matrix of detectors or a single detector. The target's radiation is then converted into an electrical signal, that is used for target detection and tracking.

\section{Aircraft infrared signatures}

The infrared signature of a body consists of its spectral radiometric characteristics inherited from a certain source, related to the radiant intensity emitted for different aspect angles. This signature depends on various factors, such as temperature, emissivity, shape and dimensions of the object in study ${ }^{4}$.

In aircrafts, the main radiation sources are:

- the hot metal from the engine exhaust;

- the exhaust gases;

- the aerodynamically heated fuselage $e^{5}$.

Furthermore, it is important to emphasize that the detector's infrared band is fundamental in the envelope determination. In this work, the mid-wavelength infrared (MWIR) band were used between 3 to $5 \mu \mathrm{m}$. In this band, the main factor that contributes to the aircraft's infrared signature is the exhaust gases plume ${ }^{5}$.

\section{Atmospheric transmittance}

Before reaching the infrared sensor, the radiant flux radiated by the target propagates through the Earth's atmosphere, causing this flux to be absorbed selectively by atmospheric gases, scattered by suspended particles in the air or even modulated by quick variations in the atmospheric properties ${ }^{6}$. All these factors compound the atmospheric transmittance.

In the MWIR, the atmospheric transmittance is composed mainly by the absorption process, that prevails over the scattering process, due to the absorption of water vapor molecules and carbon dioxide in this section of the infrared ${ }^{7}$.

\section{Infrared aircraft detection}

The crucial factor in the detection of an aircraft by an infrared missile is the contrast between the radiant intensity emitted by the aircraft against the radiant intensity emitted by the background that reaches the detector through the atmosphere.

The maximum range detection of an infrared detector can be calculated as a function of its noise equivalent irradiance (NEI), a detector's performance parameter that consists of the incident irradiance in the detector capable of generating an output signal higher than the noise level.

While the aircraft's detection is performed by the contrast in relation to the background, the irradiance that reaches the detector must be higher than a threshold level (related to the NEI). Considering the maximum detection range as R, it is obtained by Eq. $1^{2,3}$ :

$$
R^{2}=\frac{I_{c}(\theta, \varphi) \cdot \tau(R, \varphi)}{S N R \cdot N E I}
$$

in which: $\operatorname{Ic}(\theta, \varphi)=$ the contrast intensity, in the detector's spectral band, between the aircraft and the background, given in function of the elevation angle $\varphi$ and azimuth angle $\theta$ relative to the missile and the aircraft; $t(R, \varphi)=$ the effective spectral transmittance in the detector's spectral band given for the distance $\mathrm{R}$ and elevation angle $\varphi$.

Lastly, the equation's denominator is equivalent to the detection threshold, in the function of the product of the detector's NEI and the signal-to-noise ratio (SNR) value, which consists in the signal-to-noise relationship employed for target detection. 


\section{MAISA ALGORITHM}

As $t$ is a function of the distance, Eq. 1 must be iteratively solved. Therefore, we use Eq. 2 to obtain the $S N R^{*}$ value, which is the SNR obtained for a given position between the aircraft $P_{a n v}$ and the missile $P_{m i s}$.

$$
S N R^{*}\left(P_{a n v}, P_{m i s}\right)=\frac{I_{c}(\theta, \varphi) \cdot t(R, \varphi)}{N E I \cdot R\left(P_{a n v}, P_{m i s}\right)^{2}}
$$

Hence, the aircraft is considered to be detected, in a given position, when the $S N R^{\star}$ value is greater than the SNR threshold established by the missile's designer, which is determined by the detection probability and the false-alarm probability desired.

Furthermore, to predict the aircraft's detection by a MANPADS, the various uncertainties inherited from the operational scenario must be accounted for, for example:

- The MANPADS's position: given its high capability of mobility and camouflage;

- The aircraft's position: the real flight has variations regarding the planned route, due to the high dynamicity in air missions;

- Atmospheric conditions: affect directly the infrared radiation propagation emitted by the aircraft;

- Aircraft's infrared signature: during the flight, there are variations in the motor's regime power and uncertainties inherited by the measurement experiments or by the infrared signature simulations;

- MANPADS technology: the technical parameters of enemy systems are not accessible.

From solving Eq. 2, the Monte Carlo method is employed, in which the algorithm inputs assume normally distributed random values. For each $\mathrm{SNR}^{*}$ value obtained, we verified if it is higher than a detection threshold level, for the given missile in the study. After all the simulation rounds are complete, the detection probability is obtained, based on the number of rounds in which the SNR acquired was greater than the detection threshold. Fig. 1 presents the flowchart of the algorithm developed to apply the Monte Carlo method, henceforth named MAISA, to predict the aircraft's detection envelope.

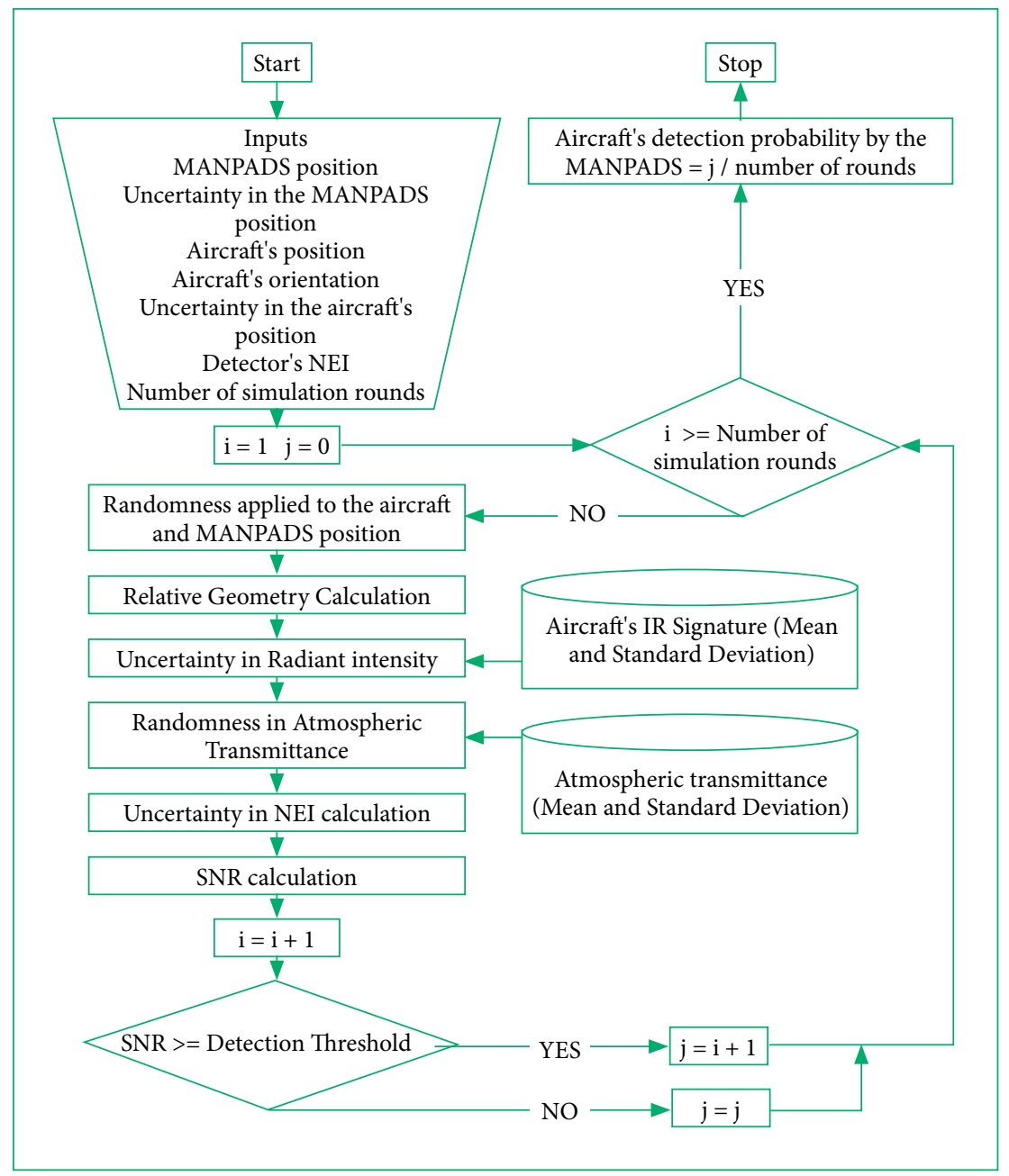

MANPADS: man-portable air-defense systems; NEI: noise equivalent irradiance; SNR: signal-to-noise ratio; IR: infrared; MAISA: surface-to-air infrared threat modulus.

Figure 1: MAISA's algorithm flowchart. 


\section{Randomness in the aircraft's and MANPADS' position}

Focusing on the mission's robustness, the planned route and the MANPADS' position must be modelled with uncertainties due to the inherited unpredictability of this operational scenario. For this, we considered the aircraft's and the MANPADS's position to undergo a random detachment, modelled by Eq. 3 .

$$
\vec{P}_{o b j_{f i n a l}}=\vec{P}_{o b j}+\Delta \overrightarrow{E_{o b j}}
$$

in which: $\vec{P}_{o b j}=$ the object's position, which can be the target or the MANPADS, in inertial coordinates; $\Delta \overrightarrow{E_{o b j}}=$ the error generated randomly in each simulation round; $\vec{P}_{o b j_{\text {final }}}=$ the object's position in inertial coordinates with the random error.

The error $\Delta \overrightarrow{E_{a n v}}$ is generated by means of Eq. 4 .

$$
\Delta \overrightarrow{E_{\text {obj }}}=\left[\begin{array}{c}
r \cdot \cos (\theta) \cdot \operatorname{sen}(\phi) \\
r \cdot \operatorname{sen}(\theta) \cdot \operatorname{sen}(\phi) \\
r \cdot \cos (\phi)
\end{array}\right]
$$

in which: $\theta$ and $\phi=$ randomized angles distributed uniformly in the interval $[0,2 \pi] ; r=$ a value given by a gaussian distribution with mean 0 and standard deviation set by the user (one value of standard deviation is used for the aircraft and another one for the MANPADS).

\section{Aircraft's infrared signature acquisition}

The target's infrared signatures were obtained by the interpolation of the measured data or obtained by simulation ${ }^{3,8,9}$. Fig. 2 shows an example of an infrared signature used. The graphic is composed of radiant intensity (z-axis) in function of various elevations ( $y$-axis) and azimuth angles (x-axis) measured. In order to introduce the uncertainties associated with the infrared signature measurement experiments or simulated infrared signature models, the user can associate an uncertainty to the infrared signature used, providing higher robustness to the MAISA result.

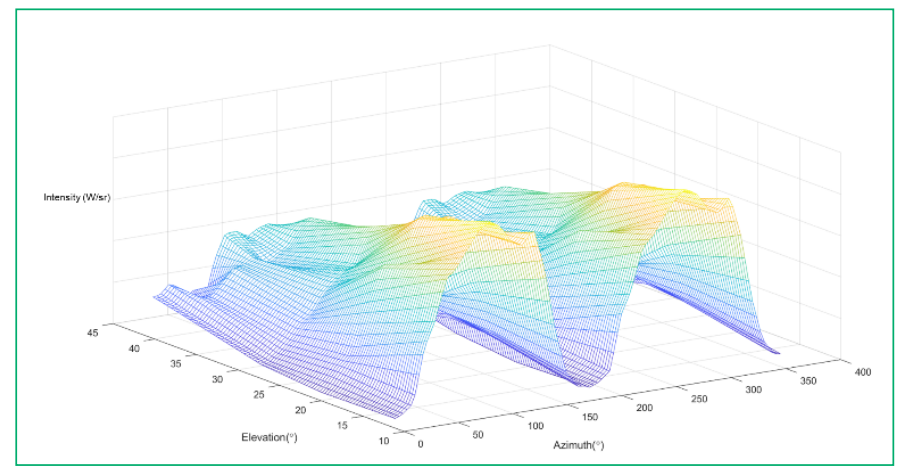

Figure 2: Values of infrared signature used in this study.

\section{Atmospheric transmittance determination}

Regarding the atmospheric transmittance, MODTRAN software was employed to obtain atmospheric transmittance values in the function of various atmospheric conditions in the MWIR band. From the tropical atmosphere, simulations were performed varying the target to detector distances, from 0,25 to $15 \mathrm{~km}$, and the zenith angles, from 15 to $75^{\circ}$. For each configuration, 18 atmospheric scenarios were simulated with different concentration percentages of water vapor, carbonic gas, and aerosols, which are the main contributors in the MWIR. For each of these scenarios, MODTRAN provided the spectral transmittance in the desired band. The spectral values obtained were reduced to a unidimensional value using the concept of effective transmittance ${ }^{11}$, assuming a linear spectral response from the sensor, that consists in the relation of radiation emitted by a black body transmitted by the atmosphere and the radiation emitted by the same body in a specified temperature. Thus, the atmospheric transmittance scalar value is weighted by the source's spectral distribution.

The effective transmittance, for a given distance R, is obtained by Eq. 5, in which the black body temperature was assumed as $900 \mathrm{~K}$, compatible with the exhaust gases temperature from the aircraft's engine, which is the main contributor of the aircraft's infrared signature in the MWIR.

$$
\tau_{\text {efet }}(\mathrm{R})=\frac{\int_{\lambda_{1}}^{\lambda_{2}} M(T, \lambda) \cdot \tau(\lambda, R) d \lambda}{\int_{\lambda_{1}}^{\lambda_{2}} M(T, \lambda) d \lambda}
$$


in which: $\tau(\lambda, R)=$ the spectral transmittance for a distance R given by MODTRAN; $M(T, \lambda)=$ obtained by Planck's law, which describes a black body's spectral radiance for a given temperature $\mathrm{T}^{6}$; the interval comprehended between $\lambda_{1}$ and $\lambda 2=$ the MWIR band, considered as 3 to $5 \mu \mathrm{m}$.

From the described process, 18 values of effective transmittance were obtained for each geometric situation specified, given by the distance and zenith angle. Figs. 3 and 4 show the mean and standard deviation values of effective transmittance used in this study.

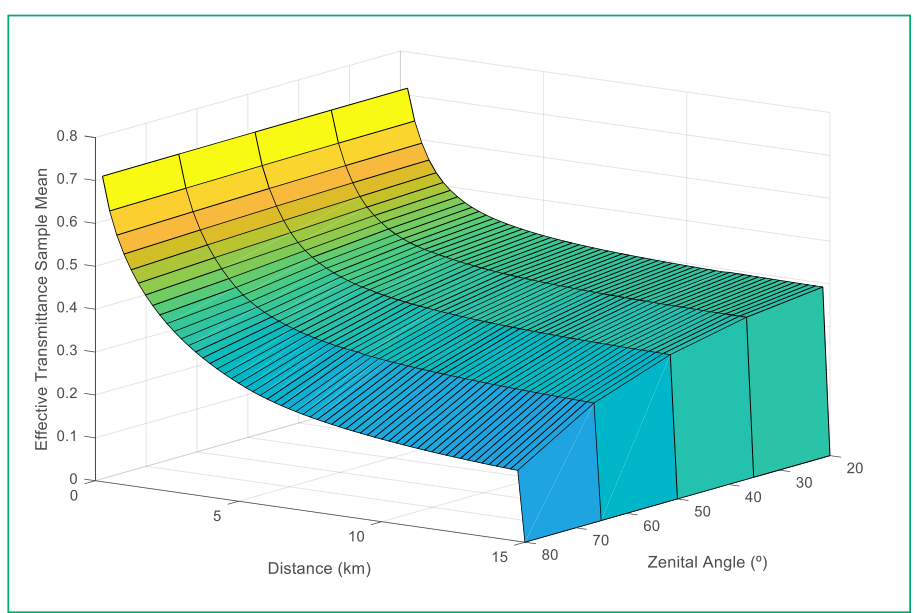

Figure 3: Effective transmittance sample mean.

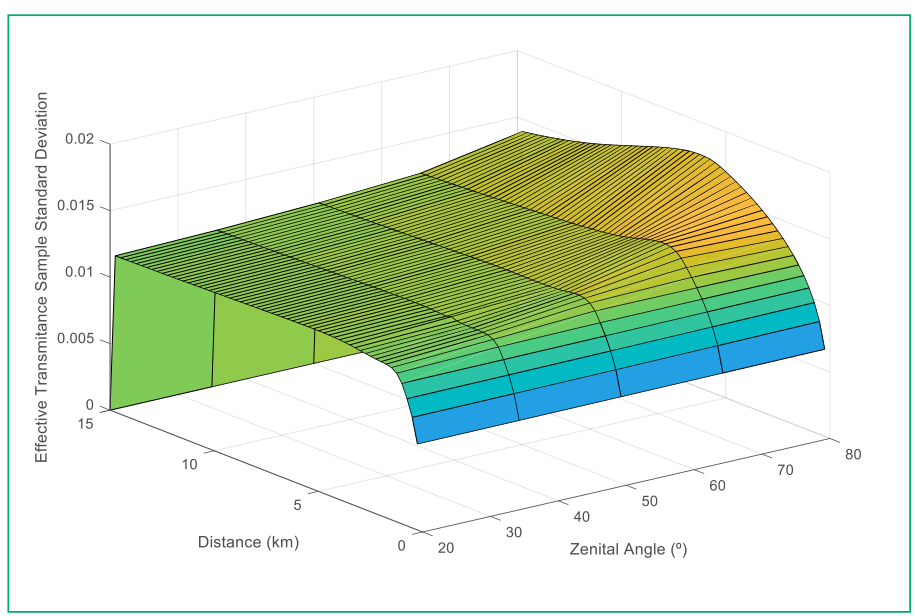

Figure 4: Effective transmittance sample standard deviation.

\section{UNCERTAINTIES IN THE MANPADS'S PARAMETERS}

In order to solve Eq. 2, the inherited parameter from the MANPADS is the NEI value, that consists of the minimum irradiance level, which is equivalent to the detector's noise RMS value. In other words, for a target to be detected, the level of radiance that reaches the detector must be greater than the NEI.

In this study, the NEI value is considered to be $2,5 \cdot 10^{-8} \mathrm{~W} / \mathrm{m}^{2}$, as the Stinger missile's NEI is taken from Rao and Mahulikar4. However, this value varies not only with the detector's type, but also individually for each detector manufactured. Therefore, from a given NEI value, a random variation is applied to this parameter in each simulation round.

Further from the NEI, the detection threshold is a different parameter for each MANPADS system, since it depends on the detection probability and the false alarm probability determined by the system's designer. In this work, the threshold level was considered to be 5 , which gives a 99\%-detection probability against a probability of false alarm of $1 \%{ }^{9,10}$.

\section{SIMULATIONS}

In an effort to analyze the information provided by MAISA as a tool of air mission planning, a hypothetical scenario was assumed, in which an aircraft must perform an incursion in a territory where a MANPADS threat exists, and its position is uncertain due to its high mobility and camouflage in the terrain. Given the parameters and uncertainties shown previously, we employed the MAISA to evaluate the aircraft's detection probability by the MANPADS in each position, from the input values presented in Table 1. 
Table 1: Input values employed.

\begin{tabular}{|c|c|}
\hline Parameter & Value \\
\hline MANPADS' position & {$\left[\begin{array}{lll}0 & 0 & 0\end{array}\right] \mathrm{m}$} \\
\hline Uncertainty in the MANPADS' position & $\sigma=333 \mathrm{~m}$ \\
\hline Uncertainty in the aircraft position & $\sigma=20 \mathrm{~m}$ \\
\hline Aircraft's position in $\widehat{\boldsymbol{x}}$ & -10 to $10 \mathrm{~km}$ \\
\hline Aircraft's position in $\widehat{\boldsymbol{y}}$ & -10 to $10 \mathrm{~km}$ \\
\hline Aircraft's height & $10 \mathrm{~m}$ \\
\hline Aircraft's orientation & $\widehat{\boldsymbol{x}}$ \\
\hline Detector's NEI & $2,5 \cdot 10^{-10} \mathrm{~W} / \mathrm{cm}^{2}$ \\
\hline Uncertainty in NEI & $10 \%$ \\
\hline Uncertainty in the infrared signature & $10 \%$ \\
\hline Detection threshold & $\mathrm{SNR}=5$ \\
\hline
\end{tabular}

MANPADS: man-portable air-defense systems; NEI: noise equivalent irradiance; SNR: signal-to-noise ratio.

Initially, the algorithm was employed without assuming randomness in the input variables. Therefore, the contour map obtained is shown in Fig. 5, in which the detection probability value was obtained for each position coordinate. The aircraft's detection distance by the MANPADS, in this case, was of $8,700 \mathrm{~m}$.

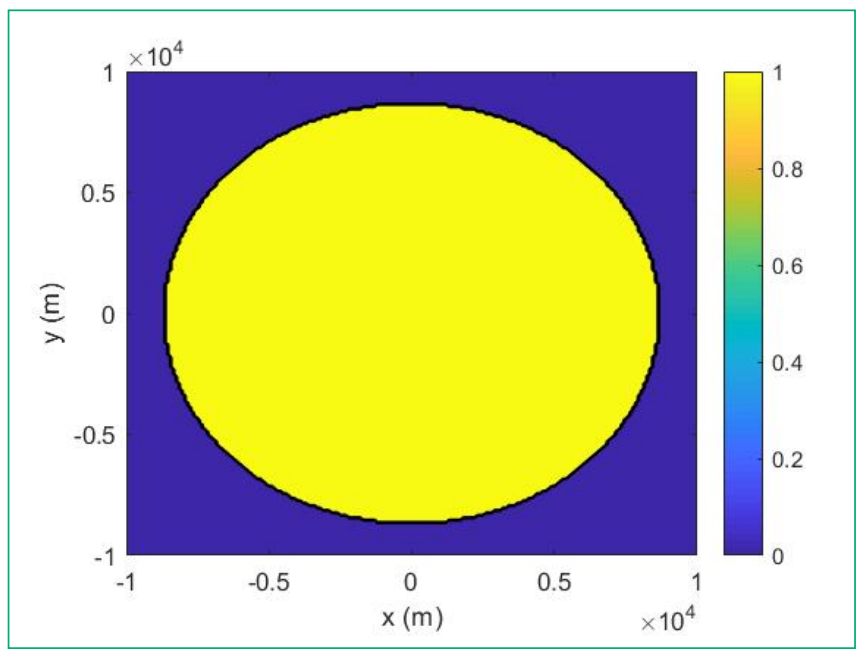

Figure 5: Detection probability contour map obtained without randomness.

Assuming the randomness of the operational scenario, the detection probability contour maps were obtained for each aircraft's position with 50, 200, and 400 rounds of simulation, which are illustrated in Figs. 6, 7, and 8, respectively.

Seeking the evaluation of the necessary simulation rounds, a figure of merit was employed as the mean absolute relative error $\Delta_{\mathrm{p}, \mathrm{q}}$ between the detection probability values obtained with two different number of rounds, $P_{d e t}^{p}$ and $P_{d e t}^{q}$, given by Eq. 6 .

$$
\Delta_{p, q}=\frac{\sum_{i=1}^{i=n}\left|\frac{\left(P_{\text {det }_{i}}^{p}-P_{\text {det }_{i}}^{q}\right)}{P_{d e t}^{q}}\right|}{n}
$$




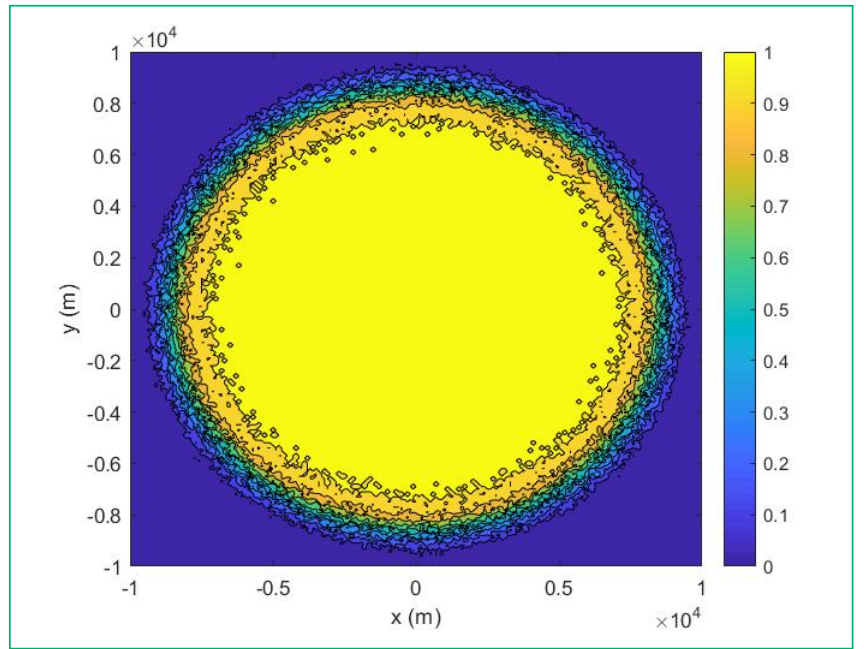

Figure 6: Detection probability contour map obtained with 50 simulation rounds.

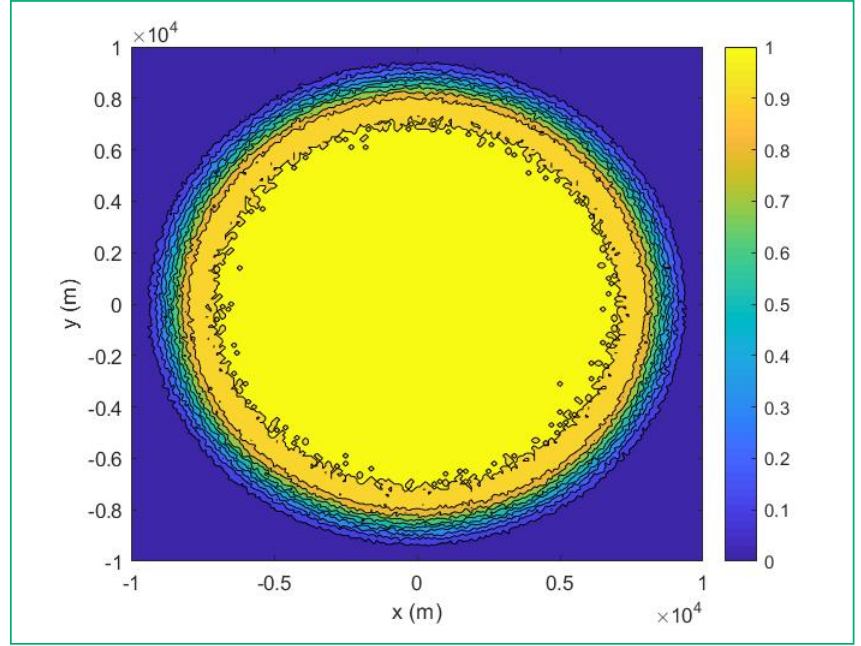

Figure 7: Detection probability contour map obtained with 200 simulation rounds.

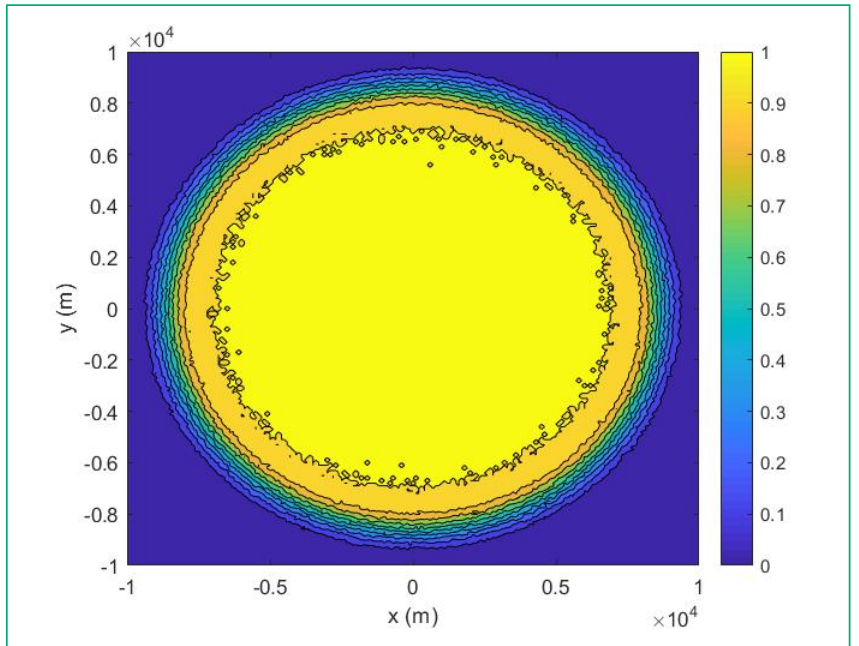

Figure 8: Detection probability contour map obtained with 400 simulation rounds.

Table 2 presents the mean absolute relative error obtained by a different number of simulation rounds. 
Table 2: Mean absolute relative error values.

\begin{tabular}{|c|c|c|}
\hline Number of rounds $\mathbf{p}$ & Number of rounds q & Mean absolute relative error (\%) \\
\hline 50 & 100 & 1,57 \\
\hline 100 & 200 & 1,12 \\
\hline 200 & 400 & 0,8 \\
\hline 400 & 800 & 0,57 \\
\hline 800 & 1,600 & 0,4 \\
\hline
\end{tabular}

From the values shown in Table 2, it was considered in this study that 400 simulation rounds are sufficient for further analysis, because the relative error was smaller than $1 \%$.

With the finality to assist the air mission planning, it was necessary to provide the decision-maker with an easy absolute interpretation of these maps. In this way, the information in the detection probability map shown in Fig. 8 must have been reduced to a simple parameter.

Therefore, the decision-maker was provided with a security radius that delimiters an area which the aircraft must avoid to maintain the detection risk below an arbitrary level. In this study, the risk was considered to be 1,5 , and $30 \%$.

From the detection probability data provided from MAISA with 400 simulation rounds, which are shown in Fig. 8, the logical operation was executed in each coordinate of the aircraft's position, in which it was verified if the detection probability were smaller or equal to the detection risk. In this way, the security distances are obtained as shown in Table 3.

Table 3: Security radius by detection risk.

\begin{tabular}{c|c|c|}
\hline Detection risk (\%) & Security radius (m) \\
\hline 30 & 5 & 9,000 \\
9,600 & 9,900 \\
\hline
\end{tabular}

Figure 9 presents the detection contour map with the security radius circles for the detection risks of 1,5 , and 30\% overlapped, illustrated by the dashed lines in the colors of red, magenta, and cyan, respectively.

In this way, the decision-maker can plan air missions and avoid areas delimited by the security radius obtained, considering the desired detection risk for the given mission.

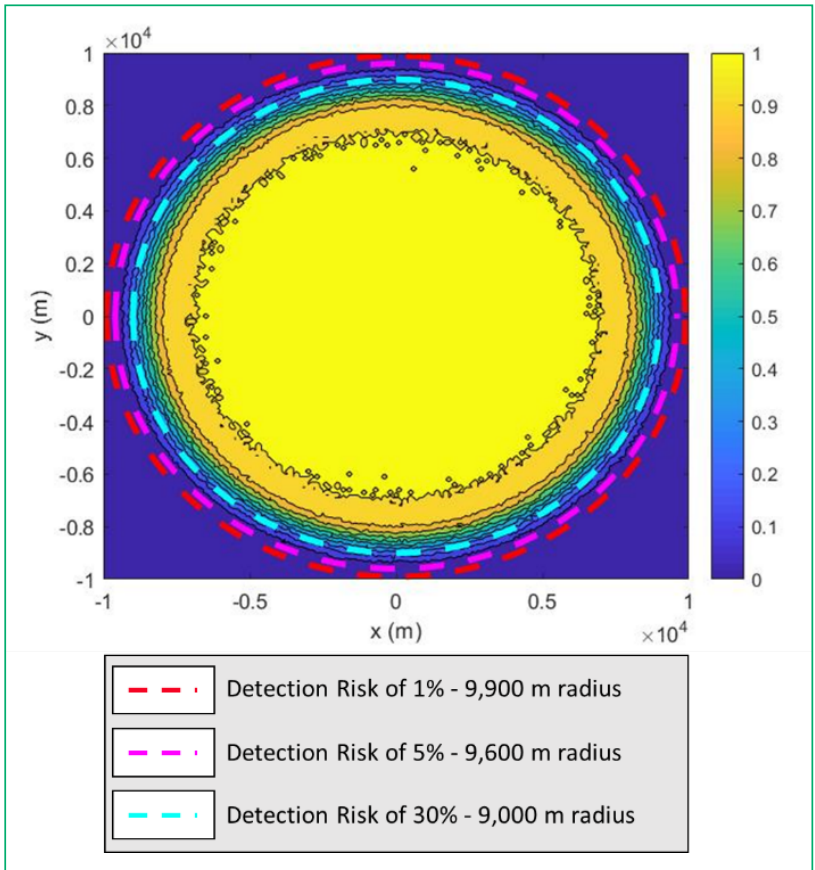

Figure 9: Probability contour map and security radius obtained with 400 simulation rounds. 
In case the operational scenario uncertainties are not considered, the decision-maker can put the air mission and the crew members at risk by underestimating the MANPADS's detection distance.

One limitation of this algorithm that must be overcome in the future is the fact that the influence of the reflected radiance of the aircraft is not considered, from the sun, the terrain, and the background in the aircraft's detection process.

\section{CONCLUSION}

The uprising threat and employment of MANPADS demand a more robust doctrine of air mission planning, that can increase the aircraft's survival probability and the mission's fulfillment. In order to promote an auxiliary tool of air mission planning in this type of scenario, an algorithm was developed to deal with such uncertainties, denominated MAISA.

It can be verified that the MAISA tool is capable of delimitating a risk area mapping the aircraft's detection probability by the MANPADS system. The algorithm takes into consideration the variations in the MANPADS's position, the aircraft's position, the atmospheric transmittance, and the MANPADS's detector NEI. With this information, in the planning moment, it is possible to define a route taking into account the acceptable risk for the mission.

\section{REFERENCES}

1. Taylor W. Protecting civil aircraft from the MANPAD threat is this a practical scenario? In: SPIE 5989, Technologies for Optical Countermeasures II. Proceedings. 2005.

2. Rao GA, Mahulikar SP. New criterion for aircraft susceptibility to infrared guided missiles. Aerosp Sci Technol. 2005;9(8):701-12. https://doi. org/10.1016/j.ast.2005.07.005

3. Werneck GR. Análise da capacidade de sobrevivência em combate de aeronaves sob ameaça de mísseis ar-ar infravermelhos [dissertation]. São José dos Campos: Instituto Tecnológico de Aeronáutica; 2016.

4. Rao GA, Mahulikar SP. Effect of atmospheric transmission and radiance on aircraft infrared signatures. J Aircraft. 2005;42(4). https://doi. org/10.2514/1.7515

5. Conant JA, LeCompte MA. Signature prediction and modelling. In: Accetta JS, Shumaker DL, eds. The infrared \& electro-optical systems handbook. Washington, D.C.: Infrared Information Analysis Center; SPIE Optical Engineering Press; 1993. v. 4. p. $301-342$.

6. Hudson RD. Infrared systems engineering. London: Wiley; 1969.

7. Willers CJ, Willers MS, Lapierre F. Signature Modelling and Radiometric Rendering Equations in Infrared Scene Simulation Systems. In: SPIE 8187, Technologies for Optical Countermeasures VII. Proceedings. 2011.

8. Ribeiro LR, Costa MV, Campos EPR, Prado G, Fávero RK, Sircilli F. Metodologia de medição de assinatura no infravermelho (AIV) de helicópteros. In: Simpósio de Aplicações Operacionais em Áreas de Defesa, 20, 2018. São José dos Campos; 2018. p. 144-9.

9. Silvestre CAM. Ferramenta de avaliação de sistemas ativos complexos de interferência em sensores infravermelhos embarcados [dissertation]. São José dos Campos: Instituto Tecnológico de Aeronáutica; 2016.

10. Accetta JS. Infrared search and track systems. In: Accetta JS, Shumaker DL, eds. The infrared \& electro-optical systems handbook. Washington, D.C.: Infrared Information Analysis Center; SPIE Optical Engineering Press; 1993. v. 5. p. 211-344.

11. Willers CJ. Electro-optical system analysis and design: a radiometry perspective. Washington, D.C.: SPIE Press; 2013. v. 1. 